\title{
Variabilidade do conteúdo iônico da neve e do firn ao longo de um transecto antártico
}

\author{
Filipe Gaudie Ley LINDAU ${ }^{1}$, Jefferson Cardia SIMÕES ${ }^{1}$, Magdalena de Mello MARQUES ${ }^{1}$, Daiane \\ Flora HAMMES ${ }^{1}$, Daniel Bayer DA SILVA ${ }^{1}$, Gino CASASSA ${ }^{2}$, Sharon SNEED ${ }^{3}$ \& Douglas INTRONE ${ }^{3}$
}

(1) Centro Polar e Climático, Universidade Federal do Rio Grande do Sul, Av. Bento Gonçalves, 9500, CEP 91.540-000, Porto Alegre, RS, Brasil. E-mail: filipe.lindau@outlook.com, jefferson.simoes@ufrgs.br, magdalena.marques@gmail.com, daianehammes@yahoo.com.br, danibayer@bol.com.br.

(2) Centro de Estudios Cientificos, Geoestudios. Los Aromos 3408, Las Vertientes, Santiago, Chile. E-mail: g.casassa@geoestudios.cl.

(3) Climate Change Institute, University of Maine, Bryand Global Sciences Center, 303, Orono, ME 04469-5790, EUA. E-mail: sharon.sneed@maine.edu, introne@maine.edu.

Recebido em 07/2014. Aceito para publicação em 04/2016. Versão online publicada em 26/08/2016 (www.pesquisasemgeociencias.ufrgs.br)

\begin{abstract}
Resumo - Com o objetivo de interpretar a variabilidade no conteúdo iônico da neve e do firn entre Patriot Hills $\left(80^{\circ} 18^{\prime} \mathrm{S}, 81^{\circ} 21^{\prime} \mathrm{W}\right)$ e o Polo Sul Geográfico, foram determinadas as concentrações dos íons majoritários e as razões isotópicas das 200 primeiras frações de cinco testemunhos de neve e firn (com profundidades de até $46 \mathrm{~m}$ ), durante a travessia chileno-brasileira ocorrida no verão de 2004-2005. Após as amostras serem limpas (em câmara fria) e derretidas (em sala limpa classe 100), os íons $\mathrm{Na}^{+}, \mathrm{K}^{+}, \mathrm{Mg}^{2+}, \mathrm{Ca}^{2+}, \mathrm{MS}^{-}\left(\mathrm{CH}_{3} \mathrm{SO}_{3}{ }^{-}\right), \mathrm{Cl}^{-}, \mathrm{NO}_{3}{ }^{-}$e $\mathrm{SO}_{4}{ }^{2-}$ foram analisados por cromatografia iônica, com limites de deteç̧ão entre 0,3 e 1,8 $\mathrm{g} \mathrm{L}^{-1}$, dependendo do íon. A razão isotópica deutério/hidrogênio $(\delta \mathrm{D})$ foi determinada com precisão de $0,5 \%$. Dataram-se as amostras, com precisão anual e exatidão de \pm 2 anos, a partir da contagem anual de camadas de neve e de firn dos perfis de $\mathrm{Na}^{+}, \mathrm{nsSSO}_{4}^{2-}$ (sulfato não proveniente do sal marinho, do inglês non-sea-salt sulfate) e $\delta \mathrm{D}$. A partir da datação obteve-se as taxas médias de acumulação líquida de neve para os sítios de cada testemunho de neve e firn, as quais apresentaram uma correlação negativa ( $\mathrm{r}>0,4$, em módulo) à medida que se aumentavam a elevação e a distância da costa, respondendo, ainda, às feições superficiais locais e à ocorrência de ventos catabáticos. Constataram-se aerossóis do sal marinho com alteração na razão $\mathrm{Na}^{+} / \mathrm{Cl}^{-}$no registro dos cinco testemunhos de neve e firn, mas a presença de aerossóis produzidos na formação do gelo marinho só foi identificada nos sítios mais próximos à costa. Os registros de $\mathrm{NO}_{3}{ }^{-}$, assim como os de MS', indicam a provável ocorrência de processos pós-deposicionais, ligados tanto a eventos vulcânicos, como a reações fotoquímicas acentuadas por superfícies com formação de esmalte de gelo.
\end{abstract}

Palavras chave: Íons majoritários, testemunhos de neve e firn, Antártica.

\begin{abstract}
IONIC VARIABILITY IN SNOW AND FIRN ALONG AN ANTARCTIC TRANSECT. In order to interpret the ionic variability in snow and firn from Patriot Hills $\left(80^{\circ} 18^{\prime} \mathrm{S}, 81^{\circ} 21^{\prime} \mathrm{W}\right)$ to the South Pole, we determined the major ions concentrations and isotopic ratios of five snow and firn cores (less than $46 \mathrm{~m}$ deep) for the 200 first fractions, collected during the 2004-2005 Chilean-Brazilian traverse. After cleaning the samples (in a cold room) and melting it (in a class 100 clean room), we determined the $\mathrm{Na}^{+}, \mathrm{K}^{+}, \mathrm{Mg}^{2+}, \mathrm{Ca}^{2+}, \mathrm{MS}^{-}\left(\mathrm{CH}_{3} \mathrm{SO}_{3}{ }^{-}\right), \mathrm{Cl}^{-}, \mathrm{NO}_{3}{ }^{-}$and $\mathrm{SO}_{4}{ }^{2-}$ concentrations by ion chromatography, with detection limits from 0.3 to $1.8 \mu \mathrm{g} \mathrm{L} \mathrm{L}^{-1}$ depending on the ion. For deuterium/hydrogen isotopic ratio $(\delta \mathrm{D})$ the precision is $0.5 \%$. We dated the samples with annual precision and \pm 2 years accuracy, by counting the $\mathrm{Na}^{+}, \mathrm{nssSO}_{4}{ }^{2-}$ (non-sea-salt sulfate) and $\delta \mathrm{D}$ annual layers. Then we obtained, for the five snow and firn cores sites, the mean net snow accumulation rates. They show a negative correlation ( $r>0.4$, module) with increasing elevation and sea distance, yet responding to local superficial features and katabatic winds occurrence. The snow and firn cores reveal alterations in the sea salt aerosols $\mathrm{Na}^{+} / \mathrm{Cl}^{-}$ratios, but the aerosols produced during sea ice formation appear only on the nearest sites of the coast. The $\mathrm{NO}_{3}{ }_{3}$, as the MS- record, indicates the occurrence of post-depositional processes connected to volcanic events and photochemical reactions, which intensity increases on glaze surfaces.
\end{abstract}

Keywords: Major ions, snow and firn cores, Antarctica. 


\section{Introdução}

O manto de gelo antártico preserva em sua estratigrafia características químicas, físicas e biológicas das massas de ar que percorreram o continente durante o quaternário. As características químicas podem fornecer a identificação e a variabilidade temporal das áreas onde são formadas as massas de ar que adentram a Antártica. Elas também possibilitam analisar o aumento dos níveis de poluição atmosférica sobre o continente, permitindo inferências sobre a variabilidade em escala global destes níveis. Ou seja, essas características têm potencial de fornecer dados para o melhor entendimento das interações entre os oceanos, a atmosfera e a criosfera e suas influências ao sistema climático global.

Testemunhos são obtidos pela perfuração vertical das camadas de neve, firn (estágio intermediário entre a neve e o gelo) e gelo localizadas nos divisores das bacias de drenagem - onde as taxas de escoamento dessas camadas são mínimas. Assume-se na análise de testemunhos de regiões polares que tanto a concentração como o fluxo (concentração multiplicada pela taxa de acumulação de neve) de uma espécie química na neve é proporcional à concentração desta na atmosfera local, e que o perfil de concentrações com a profundidade representa, portanto, o perfil temporal de concentrações das espécies na atmosfera (Legrand \& Mayewski, 1997; Wolff, 2012).

A caracterização química do manto de gelo antártico dá-se pelas análises iônica, isotópica e elementar de testemunhos de neve, firn e gelo, além da determinação dos gases presentes nas bolhas de ar encontradas no gelo. A análise iônica permite determinar as espécies majoritárias depositadas, tanto por via úmida como por via seca, na neve, revelando a presença de aerossóis primários e secundários de origem, principalmente, marinha, crustal e ácida (Legrand \& Mayewski, 1997).

As razões isotópicas de deutério/hidrogênio $(\delta \mathrm{D})$ da neve são função da temperatura de condensação permitindo, portanto, diferenciar as precipitações de inverno (isotopicamente mais leves) das de verão. Uma abordagem multiparamétrica que associa o perfil isotópico a, principalmente, marcadores cronológicos (como os horizontes de referência vulcânicos), é extensivamente utilizada no estabelecimento das cronologias dos testemunhos de neve e firn antárticos (Legrand \& Mayewski, 1997; Jouzel, 2013).

0 presente trabalho apresenta um estudo das concentrações iônicas dos íons majoritários $\mathrm{Na}^{+}$, $\mathrm{K}^{+}, \mathrm{Mg}^{2+}, \mathrm{Ca}^{2+}, \mathrm{MS}^{-}, \mathrm{Cl}^{-}, \mathrm{NO}_{3}^{-}$e $\mathrm{SO}_{4}{ }^{2-}$ ) e das razões iso- tópicas $\delta \mathrm{D}$ para cinco testemunhos de neve e firn da Antártica, com o objetivo de interpretar a variabilidade no conteúdo iônico das amostras, datadas com o auxílio das razões isotópicas, relacionando com os vários processos interligados à circulação atmosférica sobre o manto de gelo antártico na região do transecto.

\section{2 Área, materiais e métodos}

\subsection{A travessia chileno-brasileira}

A travessia chileno-brasileira do manto de gelo antártico ocorreu durante o verão austral de 2004-2005, partindo no dia 13 de novembro da estação chilena Parodi $\left(80^{\circ} 18^{\prime} \mathrm{S}, 81^{\circ} 21^{\prime} \mathrm{W}\right)$ em Patriot Hills rumo ao Polo Sul Geográfico, destino que foi alcançado em 30 de novembro. Já o retorno - quando se realizou a amostragem - à estação ocorreu no dia 31 de dezembro, completando um trajeto de aproximadamente $2.410 \mathrm{~km}$. A rota foi escolhida com base em travessias prévias ao Polo Sul Geográfico e em imagens do satélite RADARSAT com resolução de 25 m (Zamora et al., 2007).

0 comboio era formado por um trator polar Berco TL-6 que rebocava três trenós para o armazenamento da carga, dois com 6 m de comprimento e o terceiro com $3 \mathrm{~m}$. Acoplado em frente ao trator havia uma haste de $7 \mathrm{~m}$ de comprimento sustentando um Radar de Penetração do Solo -GPR- (GSSI, EUA) com transdutor de $400 \mathrm{MHz}$ destinado a detecção de fendas (Zamora et al., 2007). Todo o material foi transportado por três aviões (dois Hércules C-130 e um Ilyushin IL-76) de Punta Arenas, Chile, para a estação Parodi.

Essa travessia fez parte do programa ITASE (International Trans-Antarctic Scientific Expedition) que tem como objetivo entender como o ambiente atmosférico moderno (últimos 300 anos) está representado nas camadas superficiais do manto de gelo antártico (Mayewski et al., 2005). Atualmente o ITASE conta com mais de 200 testemunhos de neve/firn/gelo coletados ao longo de $20.000 \mathrm{~km}$ percorridos pelo continente.

\subsection{Sítios de amostragem}

Os cinco testemunhos de neve e firn (denominados BR-IC-2, BR-IC-3, BR-IC-4, BR-IC-5 e BR-IC-6) foram coletados no transecto entre $88^{\circ} 01^{\prime} \mathrm{S}$, $82^{\circ} 04^{\prime} \mathrm{W}$ e $81^{\circ} 03^{\prime} \mathrm{S}$ e $79^{\circ} 50^{\prime} \mathrm{W}$, conforme expresso na figura 1 e na tabela 2 , onde também constam outras características das amostras. Na extração desses testemunhos utilizou-se a perfuradora 
eletromecânica FELICS (Ginot et al., 2002) com broca de 8,5 cm de diâmetro e $200 \mathrm{~m}$ de cabo de aço. Nessa perfuradora as partes que entram em contato com o gelo são compostas de alumínio, aço inoxidável, polietileno e polioximetileno (Delrin (C) DUPONT). Mediram-se as temperaturas médias anuais, em cada sítio, com uma sonda dotada de uma resistência de prata. Essa medida durou $24 \mathrm{~h}$ e ocorreu a profundidades que variavam entre 10 e $15 \mathrm{~m}$.

A posição geográfica de cada sítio foi determinada por um aparelho portátil de GPS, com incerteza máxima estimada de $30 \mathrm{~m}$. Já a distância da costa foi estimada no software ArcGis 10, a partir de imagens de satélite da mínima extensão do gelo marinho - entre os anos de 1979 e 2000 (NSIDC,
EUA) - na região dos mares de Amundsen e de Bellingshausen, pela qual adentram predominantemente as massas de ar sob a Antártica Ocidental (Marquetto, 2013), responsáveis pela deposição úmida dos íons na superfície.

Os testemunhos foram cortados em seções de aproximadamente $1 \mathrm{~m}$ de comprimento, seladas em sacos de polietileno, pesadas em balança eletrônica com precisão de 0,1 g (Bioprecisa, modelo BS3000A) para determinação das densidades das seções, e armazenadas em caixas de isopor. Ao fim da travessia, as seções foram transportadas por via aérea até Punta Arenas, seguindo, sob refrigeração, à Nova Iorque e, por fim, foram levadas a Bangor (Maine, EUA) por caminhão frigorífico.

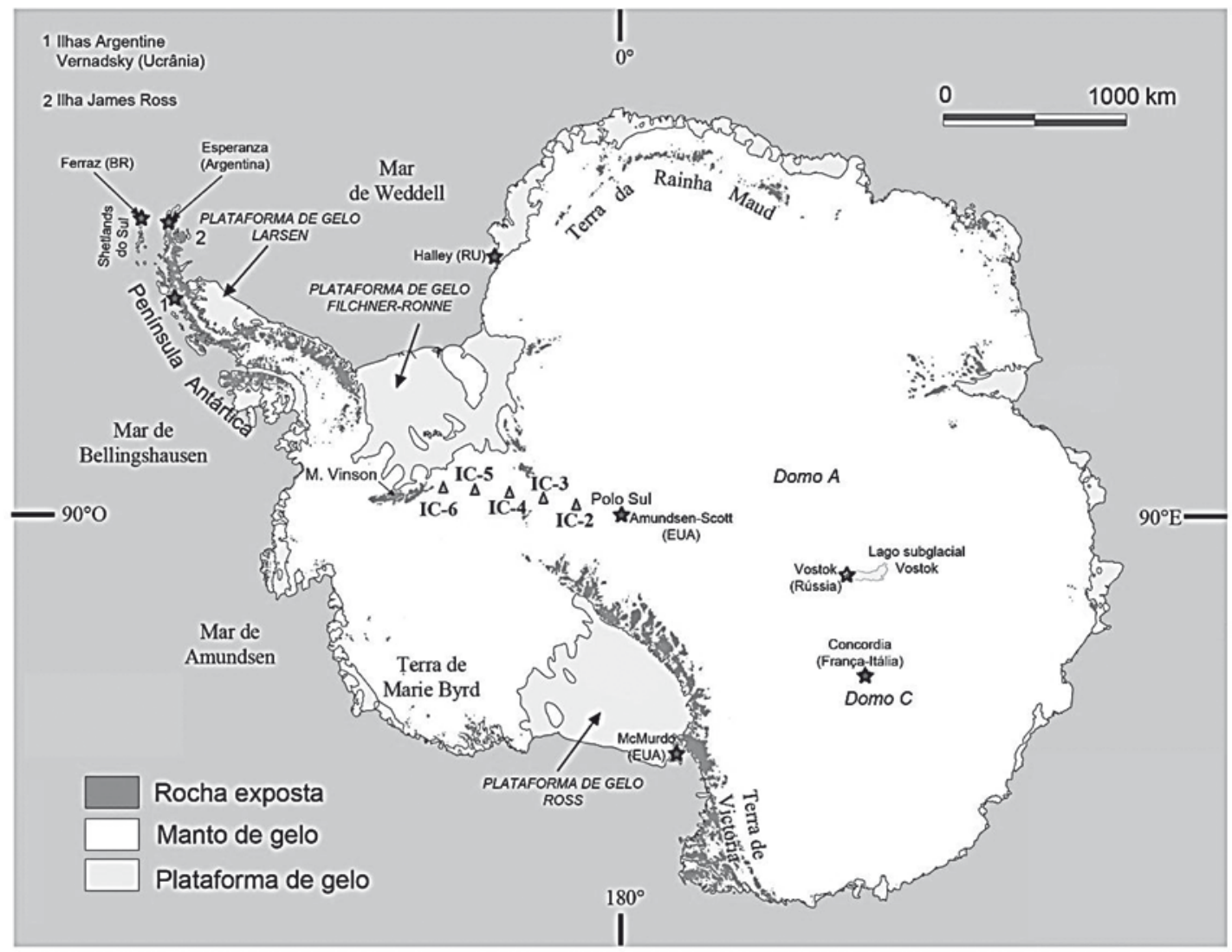

Figura 1. Principais topônimos antárticos: os triângulos indicam os cinco sítios de amostragem e as estrelas localizam algumas das estações científicas (modificado de Simões, 2011).

\subsection{Sub amostragem}

Os testemunhos, armazenados em caixas de isopor, foram transferidos de um frigorífico em Bangor (Maine, EUA) para a câmara fria do Climate Change Institute (CCI), Universidade do Maine, antes do início da sub amostragem. No interior da câmara fria, submetida a $-20^{\circ} \mathrm{C}$, as seções dos testemunhos tiveram suas laterais serradas com uma lâmina de aço. Neste processo o testemunho passou de uma geometria cilíndrica com diâmetros de, aproximadamente, $8,2 \mathrm{~cm}$ para uma geometria prismática de base quadrada com lados de, aproximadamente, 4,4 cm. Após, as extremidades de cada seção foram raspadas com facas cerâmicas de modo a retirar-se camadas entre 2 e $4 \mathrm{~mm}$ (em uma mesa de fluxo laminar localizada, também, dentro da câmara fria). Durante todo o manuseio das seções dos testemunhos usaram-se luvas de polietileno.

As seções de testemunho limpas, condicionadas em tubos acrílicos, foram derretidas em labora- 
tório limpo classe 100 pelo processo de fusão contínua do CCI (Osterberg et al., 2006). No interior de um freezer vertical submetido a $-20^{\circ} \mathrm{C}$, a fusão ocorreu pelo contato entre a base dos testemunhos e um disco de níquel 270 aquecido a temperaturas entre 15 e $25^{\circ} \mathrm{C}$, dependendo da densidade das seções, o que resultou em taxas de fusão entre 1,5 e $3 \mathrm{~cm} \cdot \mathrm{min}^{-1}$. Este disco com $70 \mathrm{~mm}$ de diâmetro e $3 \mathrm{~mm}$ de espessura era dotado de ranhuras radias de $0,2 \mathrm{~mm}$ por onde fluiu a água descongelada. Em adição, o disco possuía um anel concêntrico de 30 $\mathrm{mm}$ de diâmetro e $1 \mathrm{~mm}$ de elevação que dividia o fluxo da água em duas tubulações de politetrafluoretileno independentes. A tubulação que recebeu a água derretida na parte mais interna do disco abasteceu os frascos limpos - submetidos previamente a três enxágues e $24 \mathrm{~h}$ de molho com água deionizada Milli- $Q^{\circledR}$ (Millipore, EUA) - de polipropileno, com volume $5 \mathrm{~mL}$, destinados à análise iônica. Em paralelo, a água de degelo oriunda das ca- madas mais externas das seções dos testemunhos foi bombeada pela tubulação para os frascos de 40 $\mathrm{mL}$ (feitos de PEAD) destinados à análise isotópica. Água Milli- $Q^{\circledR}$ era bombeada durante uma hora antes do início de cada dia de trabalho e ao fim do dia eram recolhidas três amostras de branco.

\subsection{Análises químicas}

O conteúdo iônico das 200 primeiras frações derretidas de cada um dos cinco testemunhos foi determinado por cromatografia iônica em um equipamento DIONEX 500 (descrito na tabela 1), no laboratório do CCI. O amostrador automático (Gilson 215-Liquid Handler, EUA) direcionou simultaneamente as amostras para os dois sistemas (cátions e ânions). Uma atmosfera inerte de gás Hélio foi utilizada nos reservatórios de eluente e de água deionizada Milli- ${ }^{\circledR}$ com resistividade de $18,2 \mathrm{M} \Omega$.

Tabela 1. Configurações do equipamento analítico Cromatógrafo iônico Dionex 500.

\begin{tabular}{lll}
\hline Sistema & Cátions & Ânions \\
\hline Loop de injeção & $500 \mu \mathrm{L}$ & $500 \mu \mathrm{L}$ \\
\hline Fluxo & $1 \mathrm{~mL} \mathrm{~min}^{-1}$ & $1 \mathrm{~mL} \mathrm{~min}{ }^{-1}$ \\
\hline Coluna de Guarda & - & AG-11 \\
\hline Coluna Analítica & CS-12A & AS-11 \\
\hline Supressora & CSRS-300 & ASRS-300 \\
\hline Detector & CD20 & CD20 \\
\hline Eluente & MSA (20mM isocrático) & KOH (gradiente de 1mM a 8mM) \\
\hline
\end{tabular}

Os sistemas eram calibrados semanalmente com cinco soluções padrão preparadas a partir de soluções estoque mais concentradas (Ultra Scientific, EUA). Conferiam-se os resultados da calibração com a solução de referência ION-92 (National Water Research Institute, Canadá).

A metodologia utilizada para determinação dos limites de detecção do método analítico foi a EPA 300.1 - Determination of inorganic anions in drinking water by ion chromatography - em que sete soluções de água deionizada são processadas e analisadas da mesma maneira que as amostras. Estes limites foram menores que $1,8 \mu \mathrm{g} \mathrm{L}^{-1}$ (valor obtido para o cloreto) e maiores que $0,3 \mu \mathrm{g} \mathrm{L}^{-1}$ (limite de detecção do potássio).

As razões $\mathrm{D} / \mathrm{H}$ foram determinadas no $\mathrm{CCI}$ utilizando-se um cromatógrafo a gás com detector de massas (GSMS) acoplado no sistema Micromass Isoprime configurado para fluxo contínuo. A precisão da técnica é de $0,5 \%$ o para a razão D/H. Já, o parâmetro $\delta \mathrm{D}$ foi determinado em relação ao padrão de referência VSMOW - Viena Standard Mean
Ocean Water - pela seguinte expressão:

$$
\delta D_{\text {amostra }}=\frac{(D / H)_{\text {amostra }}-(D / H)_{\text {VSMOW }}}{(D / H)_{\text {VSMOW }}}
$$

\subsection{Datação}

O método de datação consistiu na sucessiva identificação e contagem de camadas anuais de neve e de firn a partir dos parâmetros $\mathrm{Na}^{+}, \delta \mathrm{D}$ e $\mathrm{nsSSO}_{4}{ }^{2-}$, os quais tiveram suas estratigrafias suavizadas pelo cálculo da média móvel a cada três medidas. Os verões foram marcados unindo-se os vales - mínimos relativos - de $\mathrm{Na}^{+}$e de $\delta \mathrm{D}$ com os máximos relativos - picos - de nssSO ${ }_{4}^{2-}$, conforme representado na figura 2 , referente ao testemunho BR-IC-4. Portanto essa datação parte da consideração de que a precipitação é bem distribuída ao longo do ano e a ressuspensão, do aerossol depositado, pelo vento é desconsiderada. 


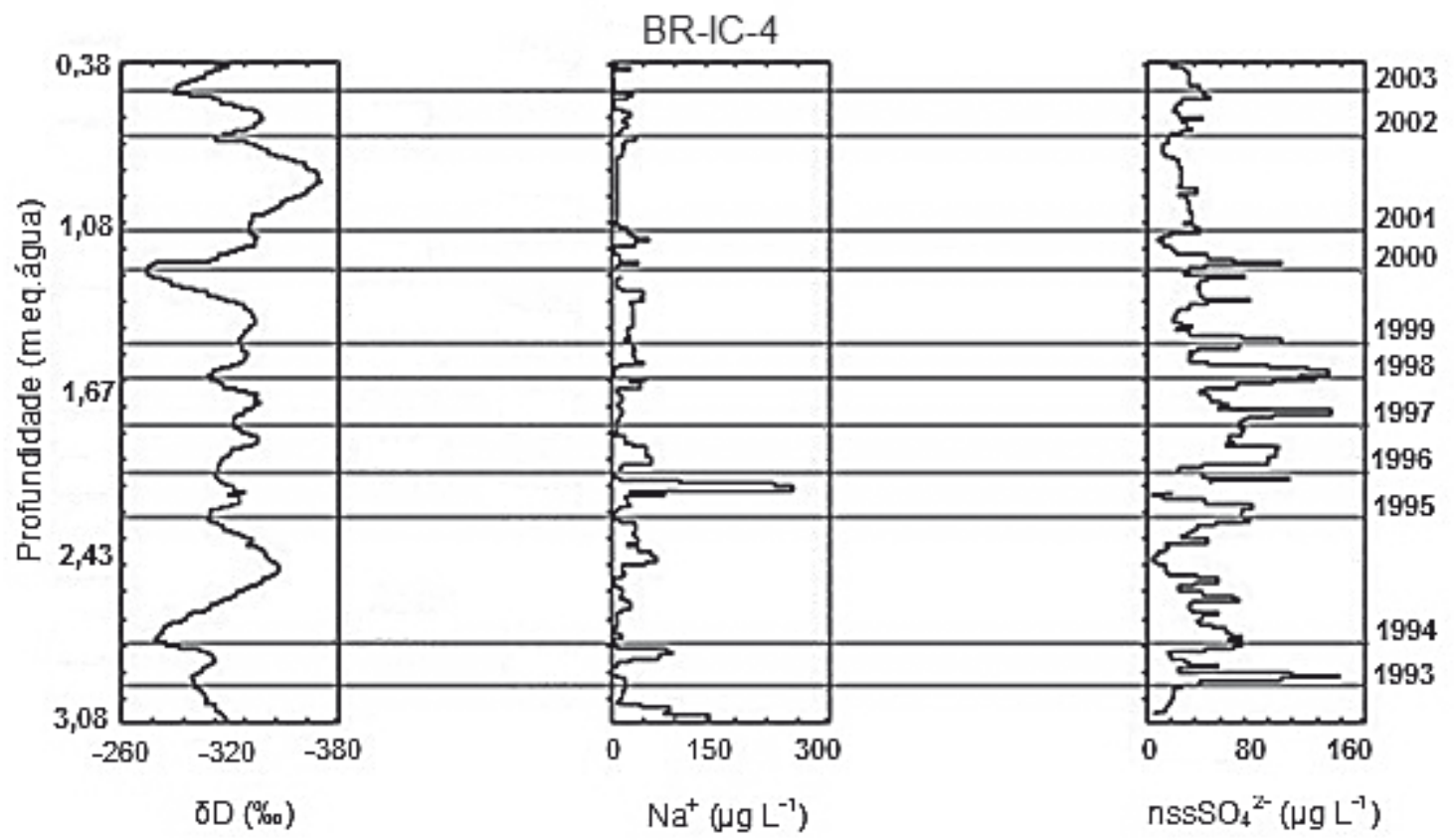

Figura 2. Estratigrafia da razão isotópica, do sódio e do sulfato não proveniente do sal marinho, respectivamente, para o testemunho BR-IC-4. As linhas horizontais marcam os verões. A profundidade é expressa em metros de equivalentes de água, que considera as variações de densidade entre as seções do testemunho.

0 parâmetro $\mathrm{nsSO}_{4}{ }^{2-}$ é derivado das concentrações (em unidades de massa) de sulfato de acordo com a seguinte equação (Traversi et al., 2004):

$n \mathrm{SSO}_{4}^{2-}=\mathrm{SO}_{4}^{2-}-\mathrm{Na}^{+}\left(\frac{\mathrm{SO}_{4}^{2-}}{\mathrm{Na}^{+}}\right)_{\text {água do mar }}$

Onde,

$\left(\frac{\mathrm{SO}_{4}^{2-}}{\mathrm{Na}^{+}}\right)_{\text {água do mar }}=0,253$

0 perfil de $\mathrm{nsSO}_{4}^{2-}$ contribui ainda na identificação de horizontes de referência, fator importante na validação do método de datação. Isto ocorre pela comparação entre o registro histórico das erupções vulcânicas cujas plumas possam ter alcançado a região Antártica, e os valores extremos no registro de $\mathrm{nsSO}_{4}{ }^{2-}$ ao longo do testemunho. As plumas estratosféricas das erupções vulcânicas tanto do Pinatubo (Filipinas), como do Cerro Hudson (Chile), ambas ocorridas em 1991, foram observadas por imagens de satélite sobre o Polo Sul Geográfico entre os meses de setembro e novembro de 1991 (Cacciani et al., 1993). Steig et al. (2005) observaram um aumento nos valores de fundo das séries temporais de $\mathrm{nsSSO}_{4}{ }^{2-}$ do US-ITASE a partir do ano de 1992, com os principais picos sendo, também, registrados neste ano. Porém somente as séries temporais dos testemunhos BR-IC-2 e BR-IC-3 chegam até o ano de 1992, as outras registram somente anos mais recentes.

Através de uma análise estatística descritiva das séries de nssSO ${ }_{4}{ }^{2-}$ observou-se a ocorrência de um valor extremo no período datado como 1993 para o testemunho BR-IC-2 e atribuiu-se a esse ponto um horizonte de referência vulcânico, devido à erupção do Pinatubo ou do Cerro Hudson. No perfil de $\mathrm{nsSO}_{4}^{2-}$ do BR-IC-3 não há valores extremos para este período, porém existem valores elevados atípicos (determinados por análise gráfica) em 1992, que podem ser atribuídos a esses eventos vulcânicos. De maneira semelhante, há para a amostra BR-IC-4 um valor classificado como atípico no ano de 1993, representado pela seção mais profunda analisada para este testemunho.

A partir das incertezas obtidas na relação entre os eventos vulcânicos e o registro de $\mathrm{nsSSO}_{4}{ }^{2-}$ nos testemunhos, atribuiu-se uma exatidão de \pm 2 anos para o método de datação utilizado. A precisão, por sua vez, é anual, pois o método permitiu a identificação de ciclos verão/inverno, principalmente a partir da série $\delta \mathrm{D}$.

\section{Resultados}

A tabela 2 apresenta os dados coletados em campo referentes aos sítios de amostragem e também, as médias amostrais das concentrações determinadas para cada parâmetro, expressas em microgramas por litro. Para o testemunho BR-IC-5 não consta a média do parâmetro metano sulfonato (MS-), pois não houve medidas suficientes para o cálculo de uma média representativa. Já a resolu- 
ção média indica o quanto as frações representam em termos de comprimento de cada amostra; apenas os testemunhos BR-IC-2 e BR-IC-3 tinham o comprimento igual à profundidade, os demais não foram analisados desde a superfície.

0 parâmetro nssCa ${ }^{2+}$ (do inglês non-sea-salt calcium) representa as contribuições não marinhas do cálcio e é definido por Bigler et al. (2006) pela seguinte equação:

$n s s C a^{2+}=c\left\{\left[\mathrm{Ca}^{2+}\right]-\left[\mathrm{Na}^{+}\right]\left(\mathrm{Ca}^{2+} / \mathrm{Na}^{+}\right)\right.$água do mar $\}$

Onde

$c=\left[1-\left(\mathrm{Na}^{+} / \mathrm{Ca}^{2+}\right)_{\text {crustal }}\left(\mathrm{Ca}^{2+} / \mathrm{Na}^{+}\right)_{\text {água do mar }}\right]^{-1}$

E

Tabela 2. Caracterização das amostras e resultados obtidos expressos como média dos resultados de cada fração analisada do respectivo testemunho.

\begin{tabular}{|c|c|c|c|c|c|}
\hline & BR-IC-2 & BR-IC-3 & BR-IC-4 & BR-IC-5 & BR-IC-6 \\
\hline Latitude $\left({ }^{\circ} \mathrm{S}\right)$ & 87,88556 & 85,99917 & 83,88917 & 82,41611 & 80,96028 \\
\hline Longitude $\left({ }^{\circ} \mathrm{W}\right)$ & 82,03139 & 81,58500 & 80,13889 & 79,39167 & 79,82111 \\
\hline Elevação (m a.s.l.) & 2621 & 1620 & 1295 & 950 & 750 \\
\hline Distância da costa (km) & 1967 & 1828 & 1694 & 1613 & 1546 \\
\hline Temperatura a $10 \mathrm{~m}\left({ }^{\circ} \mathrm{C}\right)$ & -45 & -36 & -33 & -29 & -27 \\
\hline Profundidade (m eq. água) & 3,41 & 3,83 & 3,08 & 4,33 & 3,02 \\
\hline Resolução média (cm) & 3,55 & 3,48 & 2,64 & 2,95 & 2,68 \\
\hline Período (ano) & $13 \pm 2$ & $12 \pm 2$ & $10 \pm 2$ & $8 \pm 2$ & $9 \pm 2$ \\
\hline Acumulação média (m eq. água a ${ }^{-1}$ ) & $0,26 \pm 0,05$ & $0,32 \pm 0,06$ & $0,27 \pm 0,07$ & $0,41 \pm 0,14$ & $0,30 \pm 0,08$ \\
\hline $\mathrm{Na}^{+}(\mu \mathrm{g} \mathrm{L}-1)$ & $12,54 \pm 9,24$ & $11,01 \pm 9,69$ & $26,27 \pm 35,20$ & $59,03 \pm 77,39$ & $71,58 \pm 71,90$ \\
\hline $\mathrm{K}^{+}\left(\mu \mathrm{g} \mathrm{L}^{-1}\right)$ & $1,77 \pm 11,42$ & $0,90 \pm 1,94$ & $1,61 \pm 4,89$ & $3,99 \pm 3,50$ & $3,91 \pm 2,79$ \\
\hline $\mathrm{Mg}^{2+}\left(\mu \mathrm{g} \mathrm{L}^{-1}\right)$ & $1,90 \pm 0,91$ & $1,76 \pm 1,68$ & $4,67 \pm 4,74$ & $7,96 \pm 9,08$ & $11,53 \pm 9,50$ \\
\hline $\mathrm{Ca}^{2+}\left(\mu \mathrm{g} \mathrm{L}^{-1}\right)$ & $4,75 \pm 5,59$ & $3,81 \pm 9,22$ & $35,55 \pm 19,99$ & $19,17 \pm 10,35$ & $15,23 \pm 5,42$ \\
\hline $\mathrm{MS}^{-}\left(\mu \mathrm{g} \mathrm{L}^{-1}\right)$ & $14,55 \pm 3,55$ & $12,37 \pm 6,46$ & $19,38 \pm 10,75$ & ND & $15,62 \pm 17,50$ \\
\hline $\mathrm{Cl}^{-}\left(\mu \mathrm{g} \mathrm{L}^{-1}\right)$ & $34,44 \pm 13,71$ & $32,95 \pm 21,44$ & $57,61 \pm 56,83$ & $119,07 \pm 147,42$ & $183,35 \pm 175,93$ \\
\hline $\mathrm{NO}_{3}^{-}\left(\mu \mathrm{g} \mathrm{L}^{-1}\right)$ & $68,52 \pm 31,39$ & $83,63 \pm 26,10$ & $75,74 \pm 29,32$ & $54,10 \pm 24,75$ & $67,75 \pm 33,83$ \\
\hline $\mathrm{SO}_{4}{ }^{2-}\left(\mu \mathrm{g} \mathrm{L}^{-1}\right)$ & $61,22 \pm 23,22$ & $55,62 \pm 31,24$ & $52,85 \pm 31,19$ & $39,71 \pm 24,78$ & $86,54 \pm 84,95$ \\
\hline $\operatorname{nssCa}^{2+}\left(\mu \mathrm{L} \mathrm{L}^{-1}\right)$ & $4,19 \pm 5,41$ & $3,21 \pm 8,99$ & $33,83 \pm 16,63$ & $16,59 \pm 9,89$ & $12,25 \pm 5,01$ \\
\hline $\mathrm{nssSO}_{4}^{2-}\left(\mu \mathrm{g} \mathrm{L}^{-1}\right)$ & $58,15 \pm 23,17$ & $52,89 \pm 31,57$ & $46,17 \pm 32,13$ & $32,52 \pm 23,71$ & $67,66 \pm 88,49$ \\
\hline$\delta \mathrm{D}(\%)$ & $-383,17 \pm 12,10$ & $-332,49 \pm 20,97$ & $-311,50 \pm 23,02$ & $-287,62 \pm 26,81$ & $-263,73 \pm 26,82$ \\
\hline
\end{tabular}

\section{Discussão dos resultados}

Os resultados expressos na tabela 2 são comparados entre os sítios, relacionando as características físicas determinadas em campo, com os valores obtidos a partir das análises químicas. Os resultados são discutidos, primeiramente, em re-
$\left(\mathrm{Ca}^{2+} / \mathrm{Na}^{+}\right)_{\text {água do mar }}=0,038$

Já, a relação $\left(\mathrm{Na}^{+} / \mathrm{Ca}^{2+}\right)_{\text {crustal }}$ depende da composição do aerossol crustal, que é incerta e pode ser variável ao longo do tempo, pois é função do material fonte (Bigler et al., 2006). Portanto o valor utilizado para essa relação será o da composição média da crosta de 0,562 (Bowen, 1979), a exemplo de Udisti et al. (2012).

Cada sítio teve suas taxas anuais de acumulação de neve determinadas a partir da razão entre o comprimento do testemunho e o período obtido na datação. Os valores médios dessas taxas e suas máximas incertezas constam na tabela 2 . 
das áreas fonte de aerossóis e das principais características de circulação atmosférica (e de deposição das espécies químicas) na região de estudo. Os resultados, portanto, são discutidos a partir da relação entre os íons cujas fontes e processos de transporte e deposição estão melhor estabelecidos na literatura (como o $\mathrm{Na}^{+}$, por exemplo), e os íons nos quais os mecanismos são mais complexos e apresentam maior variabilidade em diferentes regiões do continente antártico, como o $\mathrm{NO}_{3}$.

Apesar de haver valores médios de taxa de acumulação de neve para cada sítio, o que possibilitaria expressar o conteúdo iônico em termos de fluxo, os resultados são discutidos com base nas concentrações de cada íon. Com isso, busca-se facilitar a comparação dos resultados obtidos com os de outros estudos realizados em regiões próximas, pois em muitos desses estudos foram coletadas somente amostras superficiais, impossibilitando o cálculo dos fluxos de deposição a partir de parâmetros químicos.

\subsection{Variabilidade espacial das taxas médias de acu- mulação de neve}

A exemplo do que é geralmente observado no continente antártico, conforme Bertler et al. (2005), a taxa média de acumulação de neve apresenta uma significativa correlação negativa ( $\mathrm{r}>$ 0,4 em módulo), tanto com a elevação, como com a distância da costa. Entretanto, o resultado obtido para o sítio de BR-IC-3 contribui para que essa correlação não possa ser considerada forte $(r>0,8)$, pois a taxa média de acumulação determinada a partir desse testemunho de gelo apresenta um valor maior que o obtido a partir de BR-IC-4.

$O$ valor mais alto do que o esperado para taxa média de acumulação de neve encontrada em BR-IC-3 pode estar relacionado a um fenômeno local, resultante da interação entre vento, topografia e precipitação de neve.

Ao longo do trajeto da travessia foram observadas áreas cuja superfície era composta por gelo polido devido à ação do vento, ou seja, eram áreas classificadas como de glaze ice (esmalte de gelo). Isso foi constatado entre as latitudes $88,21^{\circ} \mathrm{S}$ e $86,76^{\circ} \mathrm{S}$, região que engloba o sítio de amostragem de BR-IC-2. Segundo Scambos et al. (2012) em áreas com ocorrência de esmalte de gelo, onde o vento e a sublimação removem, aproximadamente, a mesma quantidade de neve que precipita ao longo do ano, o balanço superficial de massa é próximo a zero, podendo oscilar, geralmente, de $-0,2$ a $0,2 \mathrm{~m}$ eq. água $\mathrm{a}^{-1}$. Na Antártica essas características são mais frequentemente observadas acima dos 1.500 m de altitude, em regiões com topografia favorável à circulação de ventos catabáticos (Scambos et al., 2012). Marquetto (2013), a partir da elevação medida a cada $10 \mathrm{~km}$ do transecto, observou que a região do BR-IC-2 apresenta a maior declividade favorecendo, assim, a ocorrência de ventos catabáticos.

As áreas adjacentes às superfícies de esmalte de gelo podem apresentar mais elevada acumulação de neve. Essas superfícies de acumulação são em geral rugosas, podendo apresentar dunas ou formas complexamente erodidas, tipo sastrugi, em que os cristais de neve apresentam uma granulação fina e bem sinterizada (Scambos et al., 2012). Na latitude $88,21^{\circ} \mathrm{S}$ já eram observadas feições superficiais tipo sastrugi, em meio à superfície ainda polida. Em latitudes próximas a $86,8^{\circ} \mathrm{S}$ (que inclui a do sítio de BR-IC-3) a característica superficial era rugosa. Portanto a taxa média de acumulação determinada para esse sítio pode estar acentuada devido à influência da região de esmalte de gelo.

A taxa média de acumulação de neve obtida a partir de BR-IC-6 exibe também um valor reduzido em relação a BR-IC-5, não obedecendo ao padrão esperado apesar da elevada incerteza associada a esta última concentração, resultante tanto do comprimento da amostra analisada como da incerteza da datação ( \pm 2 anos). No sítio de BR-IC-6 a proximidade das montanhas exerce influência no padrão de acumulação (Carlos, 2012). Casassa et al. (1998) observaram que a acumulação de neve reduz em pontos mais próximos à Patriot Hills, provavelmente devido erosão superficial causada pela incidência de ventos catabáticos.

\subsection{Balanço iônico}

Na figura 3 consta o balanço iônico para cada sítio de amostragem e os valores apresentados são as concentrações médias expressas em micro equivalentes por litro. $\mathrm{O} \mathrm{H}^{+}$não foi analisado, mas calculado através da seguinte expressão (Legrand \& Mayewski, 1997), a exceção do BR-IC-5 que não apresenta valor médio para o MS:

$\left[\mathrm{H}^{+}\right]=\left\{\left[\mathrm{MS}^{-}\right]+\left[\mathrm{Cl}^{-}\right]+\left[\mathrm{NO}_{3}^{-}\right]+\left[\mathrm{SO}_{4}^{2-}\right]\right\}-\left\{\left[\mathrm{Na}^{+}\right]+\left[\mathrm{K}^{+}\right]+\left[\mathrm{Mg}^{2+}\right]+\left[\mathrm{Ca}^{2+}\right]\right\}$

Outros íons são relevantes aos estudos glacioquímicos, porém contribuem de forma pouco efetiva ao balanço iônico, sem alterar significativamente os valores de $\mathrm{H}^{+}$, já que as concentrações encontradas para o íon hidrogênio têm como único objetivo ilustrar a importância das contribuições ácidas em cada testemunho. 0 fluoreto e os ácidos carboxílicos têm uma contribuição menor do que 5\% na acidez total do gelo antártico (Legrand \& 
De Angelis, 1995; Legrand \& Mayewski, 1997). Já o amônio contribui com menos de $0,2 \mu \mathrm{Eq} \mathrm{L} \mathrm{L}^{-1}$ nos balanços iônicos tanto da costa como do interior do continente antártico (Legrand \& Mayewski, 1997).

O somatório da média dos íons em cada uma das cinco amostras está dentro da faixa atribuída por Legrand \& Mayewski (1997) de 5 a $30 \mu \mathrm{Eq} \mathrm{L} \mathrm{L}^{-1}$ para testemunhos de gelo antárticos. Analisando os balanços dos cátions pode-se destacar o forte predomínio do $\mathrm{H}^{+}$em BR-IC-2 e BR-IC-3, caracte- rística que se altera no testemunho BR-IC-5, com o aumento da concentração de sódio e, também, no testemunho BR-IC-4, que registra um enriquecimento médio de cálcio. Em relação aos balanços de ânions fica evidente o predomínio de cloreto nos testemunhos BR-IC-5 e BR-IC-6, em contraste aos demais testemunhos, em que as concentrações de sulfato, nitrato e cloreto apresentam valores próximos.

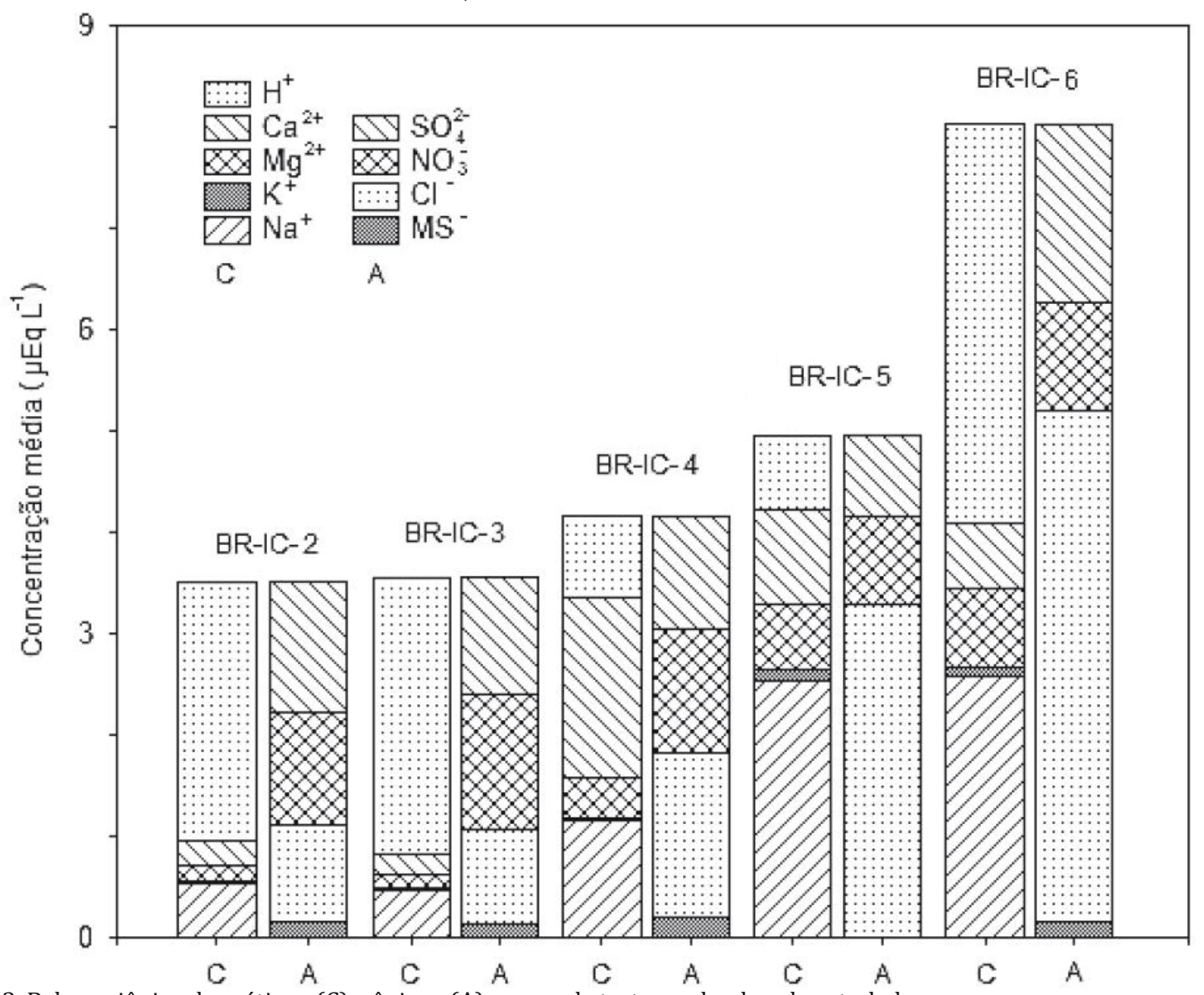

Figura 3. Balanço iônico dos cátions (C) e ânions (A) para cada testemunho de gelo estudado.

\subsection{Sódio e sal marinho}

Segundo Abram et al. (2013) há uma carga adicional de poeira crustal para todos os metais encontrados no sal marinho, a qual é muito mais significativa para o potássio, o magnésio e o cálcio do que para o sódio. Já o cloreto é submetido a fracionamento pela reação na troposfera de ácidos com o sal marinho, produzindo o ácido clorídrico. Portanto o $\mathrm{Na}^{+}$é o mais confiável marcador do sal marinho.

Em adição, o sódio é o cátion majoritário do aerossol marinho durante o inverno, tanto na costa (Wagenbach et al., 1998) como no interior do continente antártico (Udisti et al., 2012). Com a formação de gelo marinho novo, a água que ainda não congelou fica mais concentrada em sais dissolvidos, portanto o aerossol formado durante o inverno terá um maior teor de sódio. Isto ficou evidenciado pela ocorrência de valores negativos de $\mathrm{nsSO}_{4}{ }^{2-}$ em testemunhos de gelo da costa antártica, justificados pela precipitação de cristais de mirabilita $\left(\mathrm{Na}_{2} \mathrm{SO}_{4} \cdot 10 \mathrm{H}_{2} \mathrm{O}\right)$ durante a formação das frost flowers (frágeis cristais de gelo precipitados a partir do vapor d'água supersaturado em sal) que retiram cerca de metade do sulfato e aproximadamente $13 \%$ do sódio desta água mais concentrada (Rankin et al., 2002).

No interior do continente antártico, entretanto, este efeito pode estar mascarado devido às menores concentrações de nssSO ${ }_{4}^{2-}$ encontradas. Porém, outro fator está associado ao aumento em aproximadamente uma ordem de grandeza das concentrações de sódio durante o inverno. Udisti 
et al. (2012) encontraram partículas menores, na ordem sub micrométrica, durante o inverno, no aerossol coletado no Domo C (Fig. 1), revelando uma trajetória mais longa do spray marinho devido ao aumento do gradiente de pressão entre a costa e o interior da Antártica, aumentando a produção de aerossóis do sal marinho.

A tabela 3 apresenta a correlação, para cada sítio de amostragem, entre as espécies que têm o sal marinho como uma das fontes mais relevantes (Legrand \& Mayewski, 1997). Existe uma correlação positiva entre o sódio e o cloreto em todos os testemunhos, principalmente em BR-IC-4, BR-IC-5 e BR-IC-6 em que o coeficiente de correlação aproxima-se de 1,0. A correlação entre o $\mathrm{Na}^{+}$e o $\mathrm{Mg}^{2+}$ também é forte, com exceção do BR-IC-2 em que o valor de $r$ reduz consideravelmente, mas não o suficiente para descartar a presença de correlação. Já, em relação ao potássio, nota-se uma correlação significativa somente nos testemunhos BR-IC-5 e BR-IC-6.

Tabela 3. Correlações entre os principais íons do sal marinho, em cada testemunho, expressas pelo coeficiente de Pearson (r). Tamanho amostral (n) igual a 200 e confiança mínima de $95 \%$.

\begin{tabular}{cccc}
\hline & $\mathrm{Na}^{+} \times \mathrm{Cl}^{-}$ & $\mathrm{Na}^{+} \times \mathrm{K}^{+}$ & $\mathrm{Na}^{+} \times \mathrm{Mg}^{2+}$ \\
\hline BR-IC-2 & 0,89 & 0,36 & 0,54 \\
BR-IC-3 & 0,90 & 0,28 & 0,90 \\
BR-IC-4 & 0,99 & 0,26 & 0,94 \\
BR-IC-5 & 0,99 & 0,70 & 0,92 \\
BR-IC-6 & 0,97 & 0,66 & 0,90 \\
\hline
\end{tabular}

Apesar da tabela 3 indicar uma ausência de correlação entre o sódio e o potássio nos três sítios de amostragem mais afastados da costa e uma correlação mais fraca entre o sódio e o magnésio em BR-IC-2, a fonte mais provável tanto do $\mathrm{K}^{+}$como do $\mathrm{Mg}^{2+}$ continua sendo o sal marinho, conforme pode ser visto na figura 4. Nela, o potássio e o magnésio registram elevados picos de concentração nos mesmos anos em que os aerossóis do sal marinho (indicados pelo $\mathrm{Na}^{+}$) sofrem maiores deposições nos sítios BR-IC-2, BR-IC-3 e BR-IC-4. Portanto, a correlação nesses sítios indicada como inexistente, pelo valor de $r$, entre $\mathrm{Na}^{+}$e $\mathrm{K}^{+}$pode ser atribuída às baixas concentrações de potássio (próximas ao limite de detecção do método) encontradas nesses locais. Esse mesmo motivo pode ser atribuído ao menor valor de $\mathrm{r}$ na relação entre $\mathrm{Na}^{+}{\mathrm{e} \mathrm{Mg}^{2+} \mathrm{em}}^{\mathrm{a}}$ BR-IC-2, porém o testemunho BR-IC-3 registrou concentrações médias de magnésio ainda menores e, mesmo assim, há nele uma forte correlação.
A figura 4, entretanto indica um maior número de eventos extremos de concentração de $\mathrm{Mg}^{2+}$ no registro do BR-IC-3 e estes estão melhor correlacionados com o perfil de $\mathrm{Na}^{+}$.

A figura 5 apresenta para os testemunhos em estudo, a mesma abordagem utilizada por Aristarain \& Delmas (2002) quando buscavam observar de forma direta as alterações ocorridas nos aerossóis do sal marinho. A razão entre os três íons na água do mar está representada no ponto 1 (Fig. $5 \mathrm{~A}$ ), o ponto 2 refere-se à razão entre sódio e sulfato, também na água do mar, e o ponto 3 representa a razão $\mathrm{Na}^{+} / \mathrm{SO}_{4}{ }^{2-}$ no bissulfato de sódio. As amostras que apresentam concentrações acima da reta $i$ estão, portanto, enriquecidas em $\mathrm{Cl}^{-}$. Na região à esquerda da reta ii estão os pontos que apresentam concentrações negativas de $\mathrm{nssSO}_{4}{ }^{2-}$. Estes pontos indicam um enriquecimento de $\mathrm{Na}^{+}$em relação ao $\mathrm{SO}_{4}{ }^{2-}$, devido à precipitação de mirabilita durante a formação de gelo marinho, que remove mais sulfato do que sódio da salmoura formada na interface água-gelo (Rankin et al., 2002). A reta iii indica os aerossóis depositados que foram modificados durante o transporte atmosférico pela seguinte reação.

Sal marinho $+\mathrm{H}_{2} \mathrm{SO}_{4} \rightarrow \mathrm{NaHSO}_{4}+\mathrm{HCl}(\mathrm{g})$

A amostra BR-IC-2 apresenta praticamente todas as suas razões entre $\mathrm{Na}^{+}, \mathrm{Cl}^{-}$e $\mathrm{SO}_{4}^{2-}$ muito afastadas do ponto 1 (proporção referente ao sal marinho), enquanto que o testemunho BR-IC-5 registra grande parte destas razões em torno desse ponto. Nota-se, ainda, uma gradual aproximação para a razão de referência do sal marinho no sentido de BR-IC-2 a BR-IC-5. Em BR-IC-6 há uma maior dispersão das razões determinadas, quando comparado a BR-IC-5, mas elas mantêm-se concentradas em torno do ponto 1.

Todos os testemunhos de gelo analisados apresentam suas razões $\mathrm{Cl}^{-} / \mathrm{Na}^{+}$acima da razão de referência da água do mar expressa pela reta $i$ da figura 5A. Em relação a reta ii, somente as amostras BR-IC-4, BR-IC-5 e BR-IC-6 apresentam pontos a sua esquerda. Considerando a reta iii, nenhuma das amostras registra razões com elevada proporção de sulfato dispostas ao longo desta reta, como constatado por Aristarain \& Delmas (2002).

A figura 5 revela, portanto, que à medida que se afasta da costa há uma maior alteração dos aerossóis de sal marinho, pelo enriquecimento de cloreto em relação ao sódio e ao sulfato. Entretanto, a distância da costa não está correlacionada com esta alteração quando se comparam os testemunhos BR-IC-5 e BR-IC-6, pois neste caso a amos- 
tra coletada mais próxima à costa registra aerossóis depositados com maior alteração.

A contribuição de partículas oriundas do processo de formação do gelo marinho está presente somente nos três testemunhos de latitudes mais baixas. Porém, vale ressaltar que no interior do continente é mais difícil de identificar o fracio- namento que define o sal marinho proveniente do gelo marinho, pois os valores de fundo do $\mathrm{nsSO}_{4}{ }^{2-}$ originado de outras fontes (biogênica e crustal, por exemplo) é relativamente alto em comparação às baixas concentrações de sal marinho. Logo, nessa região, serão poucos os valores negativos para o $\mathrm{nssSO}_{4}{ }^{2-}$ (Abram et al., 2013).
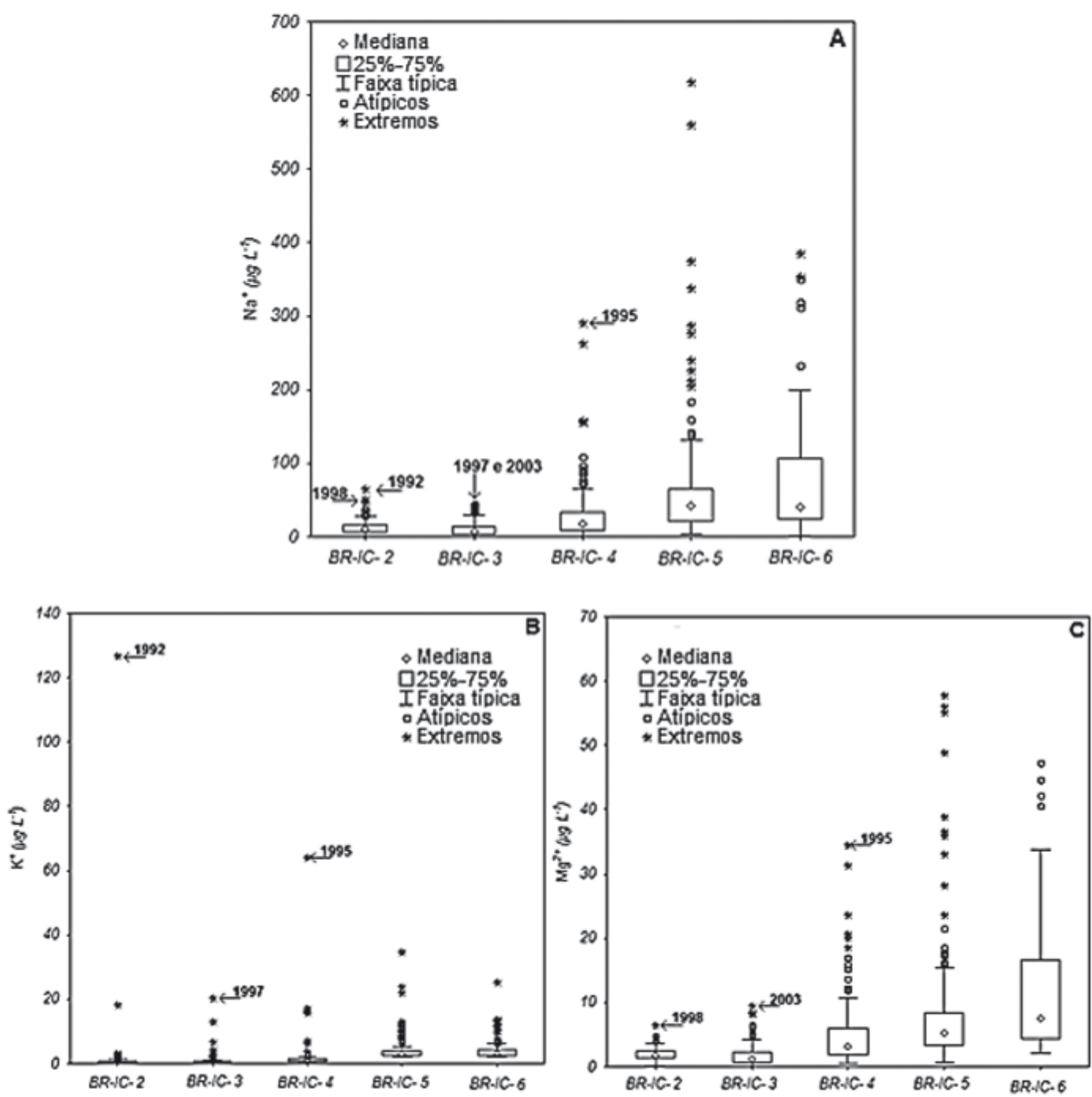

Figura 4. Diagramas de caixa referentes aos cátions $\mathrm{Na}^{+}(\mathrm{A}), \mathrm{K}^{+}(\mathrm{B})$ e $\mathrm{Mg}^{2+}(\mathrm{C})$. As datas nas quais foram registrados eventos extremos comuns a esses cátions estão indicadas por setas.

\subsection{Metano sulfonato e contribuições biogênicas}

O MS- é um dos produtos da oxidação do sulfeto de dimetila (DMS). Este, por sua vez, é originado da decomposição do propanoato de 3-dimetil sulfônico (DMSP), excretado por algas planctônicas vivas. A concentração de DMS na superfície marinha, entretanto, independe da produtividade primária, sendo que as regiões dos oceanos com maiores incidências de luz e temperaturas mais elevadas têm maiores taxas de emissão desse composto para a atmosfera (Charlson et al., 1987).

Becagli et al. (2004) observaram um suave decréscimo do MS- (em relação aos íons do sal marinho) com o aumento da distância da costa e da altitude a partir dos resultados obtidos em travessia pela Antártica Oriental durante o verão 2001/02. Esse padrão foi explicado, nesse mesmo estudo, pelo fato do ácido metano sulfônico (MSA) estar distribuído na menor fração de tamanhos entre as partículas de aerossol estudadas, permitindo que esse ácido percorra maiores distâncias antes de ser depositado na superfície em sua forma iônica. Segundo Udisti et al. (2012), o MSA está principalmente distribuído na fração sub-micrométrica dos aerossóis presentes na camada limite 
A.

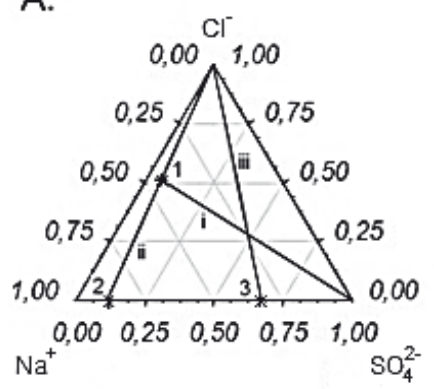

D.

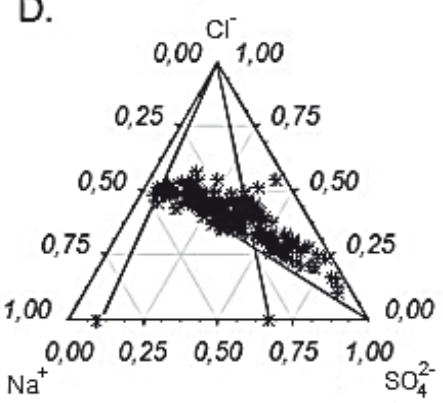

B.
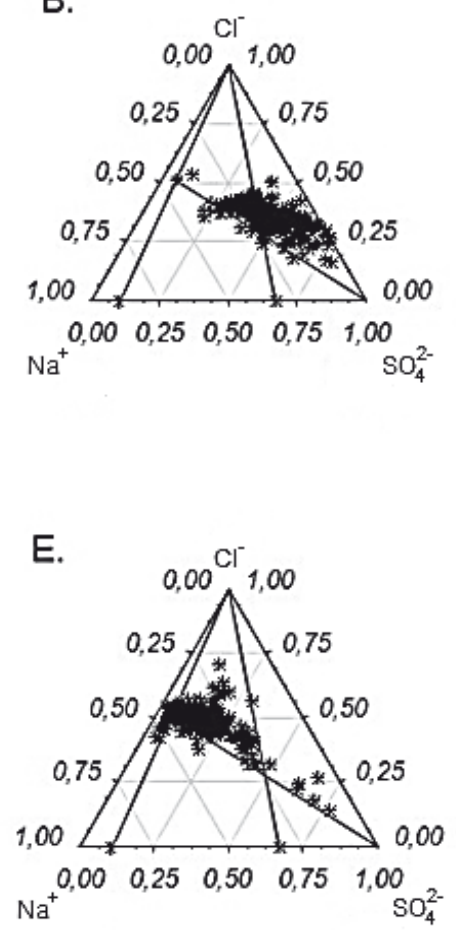

C.
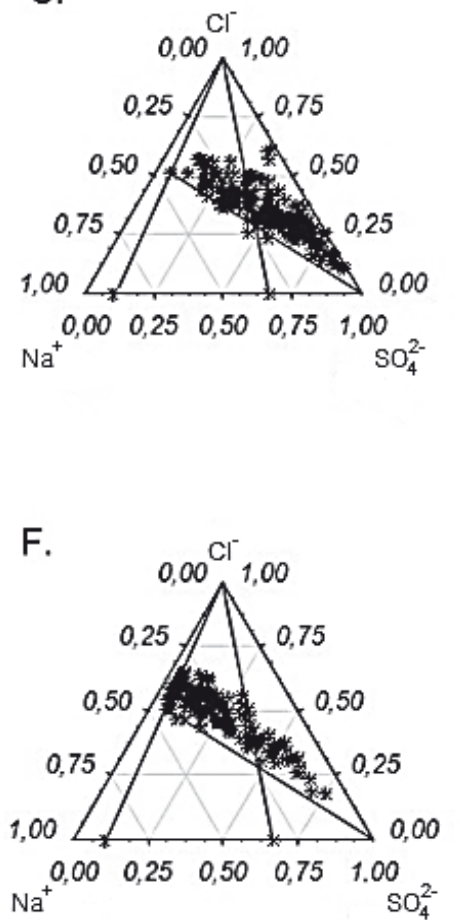

Figura 5. Diagramas ternários $\mathrm{Na}^{+}, \mathrm{Cl}, \mathrm{SO}_{4}{ }^{2-}$. A) Subdivisão das áreas por três retas (i, ii, iii) que, por sua vez, partem de três pontos (1, 2, 3); B) BR-IC-2; C) BR-IC-3; D) BR-IC-4; E) BR-IC-5; F) BR-IC-6.

atmosférica sobre o Domo C (Fig.1). Porém, Bertler et al. (2005) observaram, em seu estudo abrangendo diversas regiões da Antártica, maiores concentrações de MS- nas regiões mais próximas da costa, pois esse ânion é predominantemente depositado por via úmida e, portanto, seria mais abundante nos locais de maior taxa de acumulação de neve.

No presente trabalho a contribuição biogênica não apresenta uma clara tendência de aumento ou redução, quando avaliadas as concentrações médias de MS ao longo do transecto. Porém a análise de variância representada na figura 6 revela que há diferenças significativas entre os testemunhos. Nessa análise a variável MS- foi transformada logaritmicamente (ln), buscando uma maior homogeneidade de variância em cada testemunho.

O BR-IC-4 tem as maiores concentrações, seguido do BR-IC-2. Já os testemunhos BR-IC-3 e BR-IC-6 apresentam as menores concentrações e entre eles não existem diferenças significativas. Portanto não foi apresentada uma relação entre as concentrações de MS-, as taxas de acumulação de neve e a distância da costa.

Nos testemunhos BR-IC-3, BR-IC-4 e BR-IC-6 destacam-se alguns eventos de elevada concentração de MS', conforme indicados na figura 7. 0 testemunho BR-IC-2 não apresentou eventos de concentração extrema e a interpretação de BR-IC-5 foi descartada devido à escassez de medidas relativas a MS. Tanto em 1996 (considerando a precisão na datação de \pm 2 anos), como em 2001 foram registrados picos em BR-IC-6. 0 testemunho BR-IC-3 só registra um evento extremo em 1996 e o BR-IC-4 só apresenta concentrações destacadas em 2002.

A ocorrência desses eventos pode indicar diferentes trajetórias de massas de ar de origem marinha que adentram o continente antártico por regiões distintas. Os prováveis eventos registrados tanto em BR-IC-4 como em BR-IC-6 podem indicar a influência de massas de ar vindas do mar de Weddell, já constatada por Marquetto (2013) na região do transecto a partir de modelagem, que seriam registradas primeiramente em BR-IC-4, onde a concentração de MS foi mais elevada. Já o evento extremo registrado em BR-IC-3 e em BR-IC-6 pode representar o deslocamento de uma massa que adentra o continente antártico a partir da região dos mares de Bellingshausen-Amundsen, seguindo a direção do transecto, pois o testemunho BR-IC-6 registrou a maior concentração de MS- nesse período. Porém, por essa lógica o BR-IC-4 deveria registrar, também, um valor atípico de elevada concentração no período de $1996 \pm 2$, o que não ocorreu devido, provavelmente, a processos pós-deposicionais relacionados à taxa média de acumulação de neve registrada naquele local.

Um processo pós-deposicional associado ao MS é seu movimento pelas camadas de firn (Smith et al., 2004). Em locais de baixas taxas de acumulação da Antártica Oriental (em torno de 0,2 m eq. 


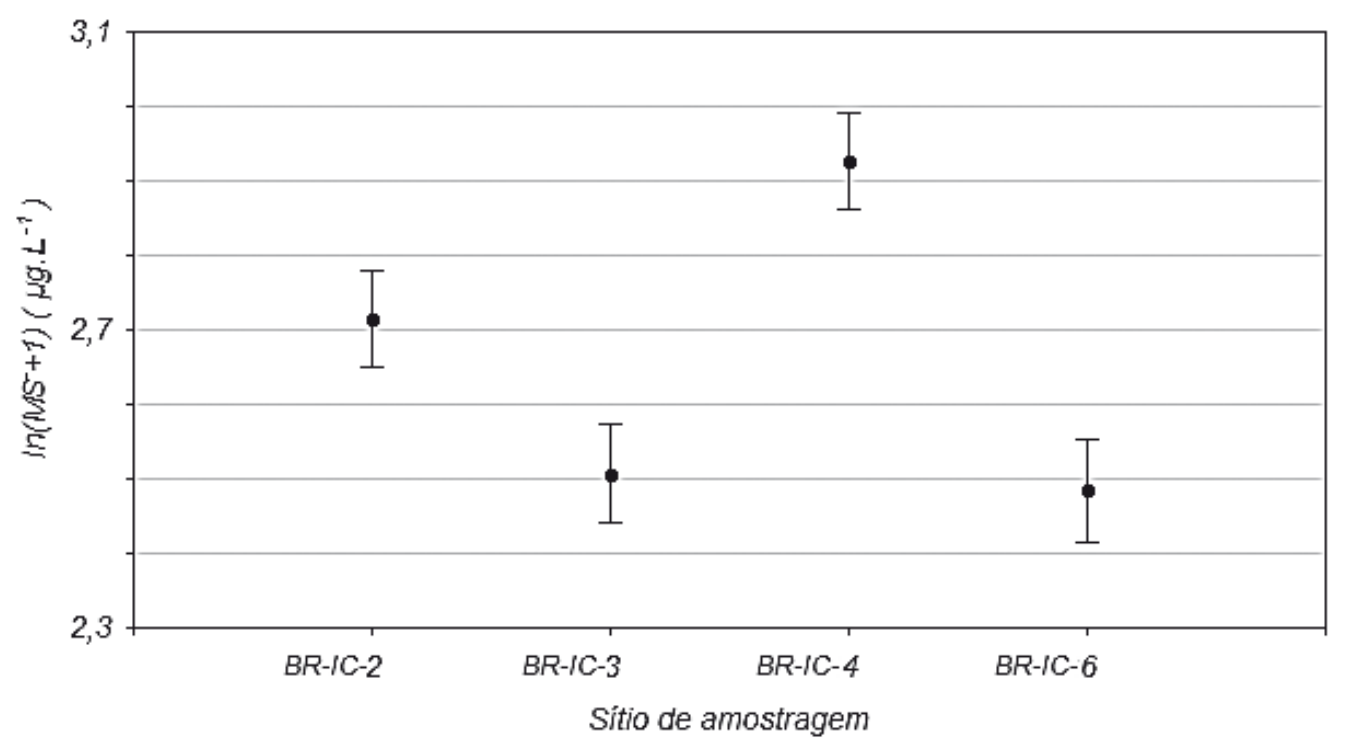

Figura 6. Resultado da análise de variância entre a variável MS- e o fator testemunho. Os pontos indicam as médias e as barras verticais representam os intervalos de confiança com certeza de 95\%.
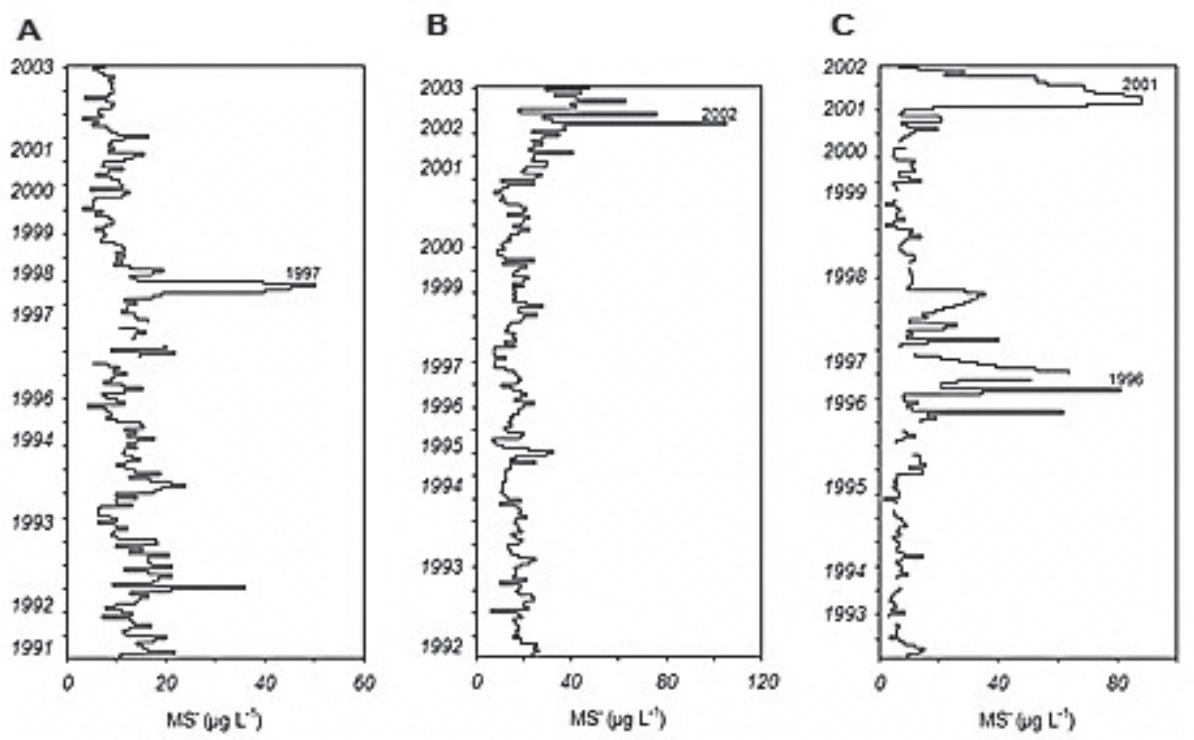

Figura 7. Séries temporais de metano sulfonato cujos eventos de concentração extrema têm seus anos indicados. A) Amostra BR-IC-3; B) BR-IC-4; C) BR-IC-6.

água) Curran et al. (2002) observaram a completa realocação dos picos de verão do MS para camadas de inverno. Segundo esses autores, uma complexa interação entre os gradientes de $\mathrm{nsSO}_{4}{ }^{2-}$, $\mathrm{NO}_{3}^{-}$e sais marinhos seria a provável responsável por controlar a taxa e a extensão dessa difusão. Já em locais com maiores taxas de acumulação de neve não foi observado tal efeito.

Portanto, pode ter havido o movimento de MS nas camadas de firn do testemunho de gelo BR-IC-4, já que a partir de seu registro foi determinada, para o seu sítio, a segunda menor taxa de acumulação dentre os sítios de amostragem do transecto, afetando o registro do evento de 1996. 0 testemunho de gelo BR-IC-2, por sua vez, registrou a menor variabilidade no perfil de MS- (Tab. 2), apesar de apresentar concentrações relativamente elevadas. Essa ausência de eventos atípicos e extremos pode, também, ser uma indicativa do mesmo efeito pós-deposicional observado em BR-IC-4.

\subsection{Cálcio e contribuições crustais}

Poeira mineral contém, geralmente, quantidades significativas de espécies solúveis contendo 
cálcio, tanto na forma de gipso $\left(\mathrm{CaSO}_{4}\right)$ e de calcita $\left(\mathrm{CaCO}_{3}\right)$ (Legrand, 1987). 0 cálcio é, também, um componente do sal marinho e as concentrações registradas em regiões remotas da Antártica, como o Domo C (Fig. 1), referentes ao período atual, mostram suas contribuições oriundas dos aerossóis de sal marinho na mesma ordem de grandeza que as suas contribuições crustais (Bigler et al., 2006).

Em contrapartida, pode ser observado, a partir da tabela 2 , que a contribuição de $n \mathrm{ssCa}^{2+}$ no valor total de $\mathrm{Ca}^{2+}$ é superior a $80 \%$ em todos os sítios de amostragem. Isso pode, portanto, ser um indicativo de uma fonte local de poeira mineral, como as montanhas Ellsworth em Patriot Hills (Fig. 1). Logo, seria de se esperar que o testemunho BR-IC-6 (coletado no sítio mais próximo a essa provável fonte) registrasse as maiores concentrações de $\mathrm{Ca}^{2+}$. Porém o testemunho BR-IC-4, além de registrar as maiores contribuições biogênicas (Fig. 6), também apresenta uma contribuição crustal muito maior que os demais testemunhos (Fig. 3). Ou seja, pode haver influência de outras regiões nas contribuições crustais nos aerossóis depositados ao longo do transecto.

\subsection{Nitrato e processos pós-deposicionais}

Bertler et al. (2005) observaram menores concentrações de nitrato nos locais com taxas de acumulação de neve mais elevadas, a partir da análise de 464 amostras espalhadas pelo continente antártico. Esse comportamento foi atribuído à influência das massas de ar de maior altitude (alta troposfera e baixa estratosfera), elevando as concentrações de nitrato nas bordas do vórtice polar. Porém $\mathrm{O} \mathrm{NO}_{3}^{-}$têm suas concentrações reduzidas, nas camadas mais superficiais de neve, devido a mecanismos físicos e fotoquímicos. Os teores de nitrato apresentam, geralmente, reduções mais significativas em locais com baixas acumulações de neve (Bertler et al., 2005; Wolff, 2012).

A análise de variância para os registros das concentrações de nitrato tem seu resultado expresso na figura 8 (em que os valores de $\mathrm{NO}_{3}{ }^{-}$estão transformadas logaritmicamente). As concentrações mais altas são encontradas no testemunho de gelo BR-IC-3 e as mais baixas no BR-IC-5. Não há diferenças significativas entre os registros de $\mathrm{NO}_{3}{ }^{-}$ de BR-IC-2 e BR-IC-4, nem entre os testemunhos de gelo BR-IC-2 e BR-IC-6. Porém as concentrações encontradas em BR-IC-4 são significativamente maiores que as do BR-IC-6.

Essa análise pode indicar, portanto, a deposição do $\mathrm{NO}_{3}^{-}$, gerado a partir do $\mathrm{NO}_{2}$ transportado pela estratosfera, via o centro de alta pressão atmosférica localizado sobre o platô polar, pois observa-se uma tendência crescente no sentido costa-interior, de BR-IC-5 a BR-IC-3. Quanto às concentrações encontradas em BR-IC-6, os valores mais elevados em relação a BR-IC-5 podem estar relacionados às maiores deposições ácidas que ocorrem no sítio de BR-IC-6. Já em relação a BR-IC-2 pode ter havido uma maior interferência dos efeitos pós-deposicionais, devido à baixa taxa de acumulação determinada para aquele sítio de amostragem.

Conforme representado nas figuras 3 e 5, o aerossol depositado no sítio de BR-IC-6 sofre maior alteração, em relação a BR-IC-5, dos sais marinhos devido a reação com espécies ácidas na troposfera, resultando no excesso de $\mathrm{Cl}^{-}$observado nesse testemunho de gelo. Portanto sua maior concentração de $\mathrm{NO}_{3}$ - deve-se, provavelmente, a maior presença de $\mathrm{HNO}_{3}$ em sua troposfera.

A formação de esmalte de gelo na superfície do sítio de BR-IC-2 pode desencadear a ocorrência de processos pós-deposicionais. Essa superfície polida transmite, em comparação a superfície de neve não modificada, mais energia solar para a camada de firn logo abaixo, permitindo que a radiação solar penetre e aqueça a camada sub superficial (Scambos et al., 2012). Logo, há um maior transporte ascendente de vapor d'água, seguido de sua condensação na base da superfície polida que, além de resultar na recristalização da neve numa granulometria mais grossa, altera as razões isotópicas $\delta \mathrm{D}$ e $\delta^{18} \mathrm{O}$ na superfície (Scambos et al., 2012; Marquetto, 2013). A presença de intervalos de profundidade, na ordem de centímetros, com cristais de gelo com granulometria mais grossa (depth hoar), foram constatadas a partir da análise estratigráfica do testemunho de gelo BR-IC-2.

A fotólise do $\mathrm{NO}_{3}$ - ocorre, preferencialmente, nos interstícios entre os cristais de gelo, por haver contato com os gases atmosféricos, formando o $\mathrm{NO}$ e o $\mathrm{NO}_{2}$ (Grannas et al., 2007). Como os processos de recristalização ocorridos em BR-IC-2 resultam no aumento do volume dos interstícios entre os cristais de gelo, há maior transformação do $\mathrm{NO}_{3}^{-}$e, portanto, maior redução nas concentrações dessa espécie ao longo do testemunho de gelo.

A partir do estudo da influência do $\mathrm{H}_{2} \mathrm{SO}_{4}$ de origem vulcânica nas concentrações de $\mathrm{NO}_{3}{ }^{-}$do testemunho de gelo NGRIP (Groelândia), Röthlisberger et al. (2002) lançaram a hipótese de outro mecanismo de remobilização do nitrato através do firn. A alta concentração de ácido sulfúrico presente na camada vulcânica causa o deslocamento para a direita no equilíbrio na reação $\mathrm{H}^{+}+\mathrm{NO}_{3}^{-} \leftrightarrow \mathrm{HNO}_{3}$, devido à existência de uma elevada quantidade de 


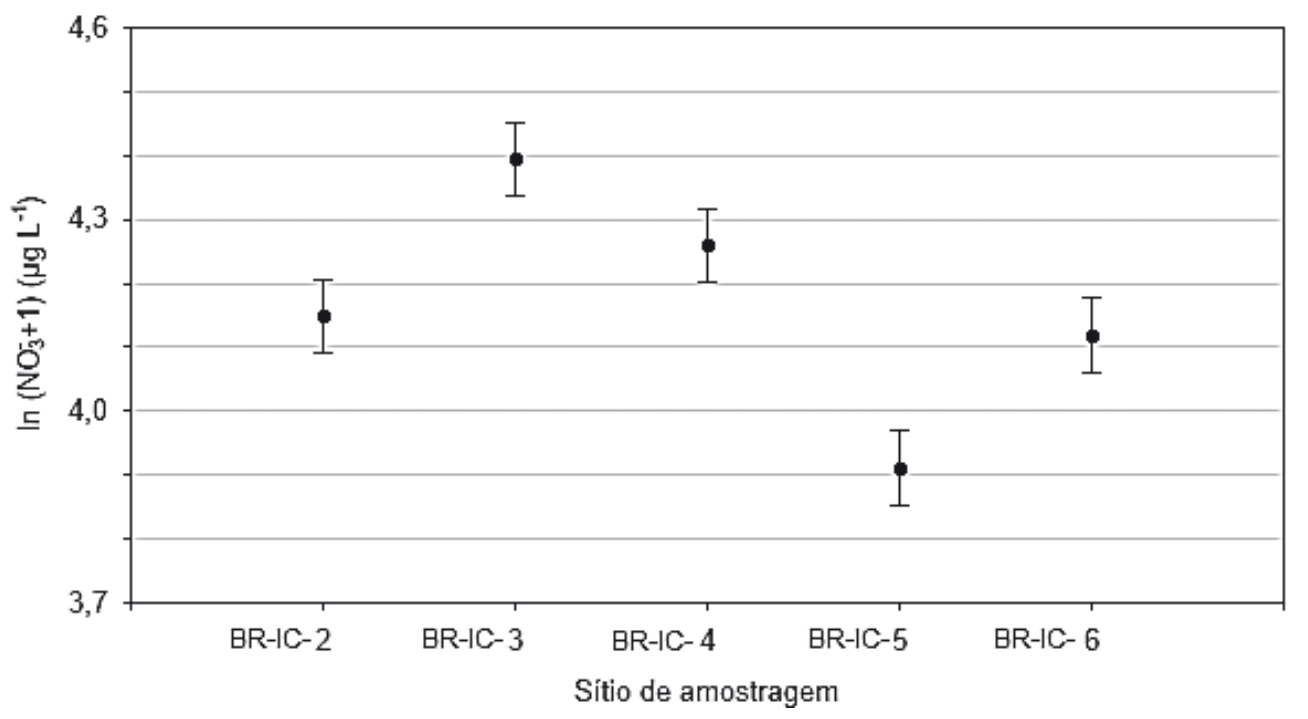

Figura 8. Resultado da análise de variância entre a variável $\mathrm{NO}_{3}^{-}$e o fator testemunho. Os pontos indicam as médias e as barras verticais representam os intervalos de confiança com certeza de $95 \%$.

$\mathrm{H}^{+}$oriundo do $\mathrm{H}_{2} \mathrm{SO}_{4}$. Logo, o $\mathrm{HNO}_{3}$ formado vai para o ar livre da estrutura do firn sofrendo, por conseguinte, difusão para uma camada adjacente de firn, onde as concentrações de ácido sulfúrico não são excessivas. Nessa nova camada o ácido nítrico volta a se dissociar em $\mathrm{H}^{+}$e $\mathrm{NO}_{3}^{-}$.

0 fenômeno descrito no parágrafo anterior pode ser o responsável pelo efeito observado no testemunho BR-IC-2, representado na figura 9, em que o evento vulcânico registrado em 1993, indicado como valor atípico de elevada concentração no diagrama de caixa do sulfato, pode ser o responsável pelo valor atípico de baixa concentração no nitrato, ocorrido no mesmo período.

\section{Conclusões}

As taxas médias de acumulação de neve mostraram-se negativamente correlacionadas com a elevação dos sítios e com suas distâncias da costa. O sítio de BR-IC-3 apresentou maiores taxas em relação a BR-IC-4, provavelmente, por tratar-se de uma área de acumulação adjacente a uma superfície de esmalte de gelo. Já, a maior incidência de ventos catabáticos no sítio do BR-IC-6, pode ter reduzido sua taxa média de acumulação de neve em comparação a BR-IC-5.

Uma relação entre a taxa média de acumulação de neve, o MS- e a distância da costa mostrou-se inexistente. Os registros de MS indicam, provavelmente, a influência de massas de ar com trajetórias distintas sobre a região do transecto. Além disso, a falta de registros de eventos esperados nos testemunhos de gelo dos sítios que apresentaram menores taxas de acumulação (BR-IC-2 e

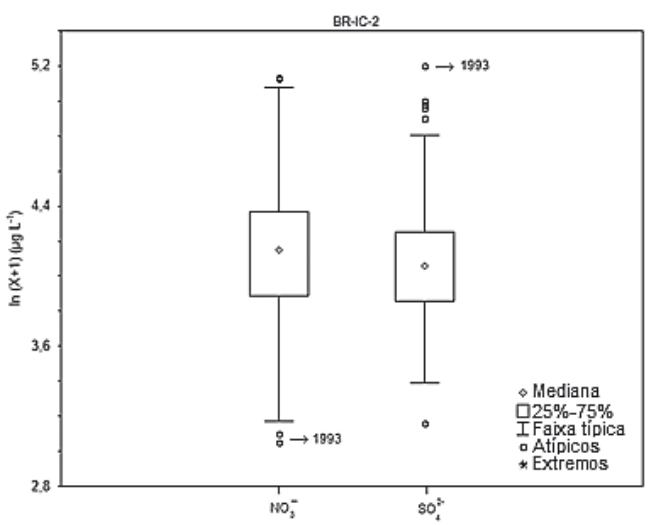

Figura 9. Diagrama de caixas em que são indicadas por setas as respostas do $\mathrm{NO}_{3}{ }^{-}$e do $\mathrm{SO}_{4}{ }^{2-}$ ao evento vulcânico registrado em 1993. As concentrações foram transformadas logaritmicamente visando a melhor identificação dos valores atípicos.

BR-IC-4) pode ser um indicativo da ocorrência do processo pós-deposicional de difusão do MS- pelas camadas de firn. As análises de MS das camadas mais profundas, incluindo as de BR-IC-5, possibilitarão identificar mais eventos destacados, permitindo relacioná-los quanto à intensidade e período de ocorrência, o que poderá levar a identificação de padrões de deslocamento das massas de ar na região.

A maior intensidade do centro de alta pressão polar sobre os sítios mais continentais pode estar relacionada com a variabilidade das concentrações de $\mathrm{NO}_{3}^{-}$ao longo do transecto. 0 decréscimo das concentrações de $\mathrm{NO}_{3}^{-}$em BR-IC-2 pode ser, portanto, um indicativo de processos pós-deposicionais resultantes da baixa taxa de acumulação local. A existência de eventos vulcânicos mais pretéritos, obtidos a partir da análise das camadas mais internas do BR-IC-2, permitirá estudar com mais detalhe suas influências no registro de $\mathrm{NO}_{3}$. A origem 
do $\mathrm{HNO}_{3}$ depositado no sítio do BR-IC-6 poderá ser explorada com mais detalhes a partir da análise de $\mathrm{NH}_{4}{ }^{+}$, das frações ainda não analisadas dos testemunhos de gelo do transecto.

Os aerossóis do sal marinho, depositados em todos os sítios, sofreram alteração durante seu transporte atmosférico ou durante sua deposição nas camadas superficiais de neve. As menores alterações ocorreram no sítio BR-IC-5. Nos cinco testemunhos de gelo, tanto $\mathrm{K}^{+}$como o $\mathrm{Mg}^{2+}$ são predominantemente depositados a partir de aerossóis do sal marinho. Já a deposição de aerossóis oriundos do processo de formação do gelo marinho só foi observada nos testemunhos de gelo dos sítios mais próximos à costa (BR-IC-4, BR-IC-5 e BR-IC-6).

A origem do $\mathrm{Ca}^{2+}$ mostrou ser predominantemente crustal nos cinco testemunhos de gelo analisados. As maiores concentrações de $\mathrm{Ca}^{2+} \mathrm{ob}-$ servadas em BR-IC-4 indicam, provavelmente, a influência de outras fontes de poeira crustal, além das áreas de rocha exposta existentes em Patriot Hills.

Agradecimentos - Este estudo é parte das investigações do Programa Antártico Brasileiro (PROANTAR) e foi financiado por projetos de pesquisa do Conselho Nacional de Desenvolvimento Científico e Tecnológico (CNPq), processos 558117/2005-8 e 557053/2009-9. F. Lindau agradece à Coordenação de Aperfeiçoamento de Pessoal de Nível Superior (CAPES) por sua bolsa de mestrado. Os trabalhos de campo foram uma ação colaborativa do Centro de Estudios Científicos de Valdívia (Chile) e o Centro Polar e Climático da UFRGS. Agradecemos à contribuição de Ronaldo T. Bernardo, Isaías U. Thoen, Franciéle S. Carlos, Luciano Marquetto, Rosemary Vieira, Masiel Neculpan, Ingrid L. Rosenhaim, Enoil S. Júnior e Carolina L. Simões no processamento dos testemunhos de neve e firn.

\section{Referências}

Abram, N., Wolff, E. \& Curran, M. 2013. A review of sea ice proxy information from polar ice cores. Quaternary Science Reviews, 79: 168-183.

Aristarain, A. \& Delmas, R. 2002. Snow chemistry measurements on James Ross Island (Antarctic Peninsula) showing sea-salt aerosol modifications. Atmospheric environment, 36: 765-772.

Becagli, S., Proposito, M., Benassai, S., Flora, O., Genoni, L., Gragnani, R., Largiuni, O., Pili, S., Severi, M., Stenni, B., Traversi, R., Udisti, R. \& Frezzotti, M. 2004. Chemical and isotopic snow variability in East Antarctica along the 2001/02 ITASE traverse. Annals of Glaciology, 39: 473-482.

Bertler, N., Mayewski, P., Aristarain, A., Barret, P., Becagli, S., Bernardo, R., Bo, S., Xiao, C., Curran, M., Qin, D., Dixon, D., Ferron, F., Fischer, H., Frey, M., Frezzotti,
M., Fundel, F., Genthon, C., Gragnani, R., Hamilton, G., Handley, M., Hong, S., Isaksson, E., Kang, J., Ren, J., Kamiyama, K., Kanamori, S., Kärkäs, E., Karlöf, L., Kaspari, S., Kreutz, K., Kurbatov, A., Meyerson, E., Ming, Y., Zhang, M., Motoyama, H., Mulvaney, R., Oerter, H., Osterberg, E., Proposito, M., Pyne, A., Ruth, U., Simões, J., Smith, B., Sneed, S., Teinilä, K., Traufetter, F., Udisti, R., Virkkula, A., Watanabe, O., Williamson, B., Winther, J., Li, Y., Wolff, E., Li, Z. \& Zielinski, A. 2005. Snow chemistry across Antarctica. Annals of Glaciology, 41: 167-179.

Bigler, M., Röthlisberger, R., Lambert, F., Stocker, T. \& Wagenbach, D. 2006. Aerosol deposited in East Antarctica over the last glacial cycle: Detailed apportionment of continental and sea-salt contributions. Journal of Geophysical Research, 111: D08205.

Bowen, H. 1979. Environmental chemistry of the elements. Londres, Academic Press, 333p.

Cacciani, M., Girolamo, P., Sarra, A., Fiocco, G. \& Fua, D. 1993. Volcanic aerosol layers observed by lidar at South Pole, September 1991 - June 1992. Geophysical Research Letters, 20(9): 273-284.

Carlos, F. 2012. Determinação de elementos traços em testemunhos de firn antártico usando espectometria de massa. Porto Alegre, 112p. Dissertação de Mestrado, Programa de Pós-graduação em Geociências, Instituto de Geociências, Universidade Federal do Rio Grande do Sul.

Casassa, G., Brecher, H., Cárdenas, C. \& Rivera, A. 1998. Mass balance of the Antarctic ice sheet at Patriot Hills. Annals of Glaciology, 27: 130-134.

Charlson, R., Lovelock, J., Andreae, M. \& Warren, S. 1987. Oceanic phytoplankton, atmospheric sulphur, cloud albedo and climate. Nature, 326: 655-661.

Curran, M., Palmer, A., Van Ommen, T., Morgan, V., Phillips, K., McMorrow, A. \& Mayewski, P. 2002. Post deposicional movement of methanesulphonic acid at Law Dome, Antarctica, and influence of accumulation rate. Annals of Glaciology, 35(1): 333-339.

Ginot, P., Stampfli, F., Schwikowski, M. \& Gäggeler, H. 2002. FELICS, a new ice core drilling system for high-altitude glaciers. Memoirs of National Institute of Polar Research, Special Issue, 56: 38-48.

Grannas, M., Jones, A., Dibb, J., Ammann, M., Anastasio, C., Beine, H., Bergin, M., Bottenheim, J., Boxe, C., Carver, G., Chen, G., Crawford, J., Dominé, F., Frey, M., Guzmán, M., Heard, D., Helmig, D., Hoffmann, M., Honrath, R., Huey, L., Hutterli, D., Jacobi, H., Klán, P., Lefer, B., McConnell, J., Plane, J., Sander, R., Savarino, J., Shepson, P., Simpson, W., Sodeau,J., Glasow, R., Weller, R., Wolff, E. \& Zhu, T. 2007. An overview of snow photochemistry: evidence, mechanisms and impacts. Atmospheric Chemistry and Physics Discussions, 7: 4165-4283.

Jouzel, J. 2013. A brief history of ice core science over the last 50 yr. Climate of the Past, 9: 2525-2547.

Legrand, M. 1987. Chemistry of antarctic snow and ice. Journal de Physique, 3(C1): 77-86.

Legrand, M. \& De Angelis, M. 1995. Origins and variations of light carboxilic acids in polar precipitation. Journal of Geophysical Research, 100(D1): 1445- 
1462.

Legrand, M. \& Mayewski, P. 1997. Glaciochemistry of polar ice cores: a review. Reviews of Geophysics, 35(3): 219-243.

Marquetto, L. 2013. Variabilidade das razões de isótopos estáveis de oxigênio na neve ao longo de um transecto antártico. Porto Alegre, 60p. Dissertação de Mestrado, Programa de Pós-Graduação em Geociências, Instituto de Geociências, Universidade Federal do Rio Grande do Sul.

Mayewski, P., Frezzotti, M., Bertler, N., Van Ommen, T., Hamilton, G., Jacka, T., Welch, B., Frey, M., Qin, D., Ren, J., Simões, J., Fily, M., Oerter, H., Nishio, F., Isaksson, E., Mulvaney, R., Holmund, P., Lipenkov, V. \& Goodwin, I. 2005. The International Trans-Antarctic Expedition (ITASE): an overview. Annals of Glaciology, 41: 180185.

Osterberg, E., Handley, M., Sneed, S., Mayewski, P. \& Kreutz, K. 2006. Continuous ice core melter system with discrete sampling for major ion, trace element, and stable isotope analyses. Environmental Science and Technology, 40: 3355-3361.

Rankin, A., Wollf, E. \& Martin, S. 2002. Frost flowers: implications for tropospheric chemistry and ice core interpretation. Journal of Geophysical Research, 107(D23): 4683-4700.

Röthlisberger, R., Hutterli, M., Wolff, E., Mulvaney, R., Fischer, H., Bigler, M., Goto-Azuma, K., Hansson, M., Ruth, U., Andersen, M. \& Steffensen, J. 2002. Nitrate in Greenland and Antarctic ice cores: a detailed description of post deposicional processes. Annals of Glaciology, 35: 209-216.

Scambos, T., Frezzotti, M., Haran, T., Bohlander, J., Lenaerts, J., Van den Broeke, M., Jezek, K., Long, D., Urbini, S., Farness, K., Neumann, T., Albert, M. \& Winther, J. 2012. Extent of low-accumulation 'wind glaze' areas on the East Antarctic plateau: implications for continental ice mass balance. Journal of Glaciology, 58(210): 633-647.

Simões, J.C. 2011. 0 ambiente antártico: domínio de ex- tremos. In: Simões, J.C., Garcia, C.A. E., Evangelista, H., Campos, L.S., Mata, M.M. \& Bremer, U.F. (Eds.). Antártica e as Mudanças Globais: um desafio para humanidade. São Paulo, Edgard Blucher, p. 15-28.

Smith, B., Van Ommen, T. \& Curran, M. 2004. Methanesulphonic acid movement in solid ice cores. Annals of Glaciology, 39: 540-544.

Steig, E., Mayewski, P., Dixon, D., Kaspari, S., Frey, M., Schneider, D., Arcone, S., Hamilton, G., Spikes, V., Albert, M., Meese, D., Gow, A., Shuman, C., White, J., Sneed, S., Flaherty, J. \& Wumkes, M. 2005. High-resolution ice cores from US ITASE (West Antarctica): development and validation of chronologies and determination of precision and accuracy. Annals of Glaciology, 41: 77-84.

Traversi, R., Becagli, S., Castellano, E., Largiuni, O., Migliori, A., Severi, M., Frezzotti, M. \& Udisti, R. 2004. Spatial and temporal distribution of environmental markers from coastal to plateau areas in Antarctica by firn core chemical analysis. International Journal of Environmental Analytical Chemistry, 84(6-7): 457-470.

Udisti, R., Dayan, U., Becagli, S., Busetto, M., Frosini, D., Legrand, M., Lucarelli, F., Preunkert, S., Severi, M., Traversi, R. \& Vitale, V. 2012. Sea spray aerosol in central antarctica. Present atmospheric behaviour and implications for paleoclimatic reconstructions. Atmospheric Environment, 52: 109-120.

Wagenbach, D., Ducroz, F., Mulvaney, R., Keck, L., Minikin, A., Legrand, M., Hall, J. \& Wolff, E. 1998. Sea-salt aerosol in coastal Antarctic regions. Journal of Geophysical Research, 103(D9): 10961-10974.

Wolff, E. 2012. Chemical signals of past climate and environment from polar ice cores and firn air. Chemical Society Reviews, 41: 6247-6258.

Zamora, R., Casassa G., Rivera, A., Ordenes, F., Neira, G., Araya, L., Mella, R. \& Bunster, C. 2007. Crevasse detection in glaciers of southern Chile and Antarctica by means of ground penetrating radar. IAHS, 318: $1-10$.

Man 547

Editores: César L. Schultz \& Paulo A. Souza. 